\title{
Active-Disturbance-Rejection-Control for Temperature Control of the HVAC System
}

\author{
Chun-E. Huang*, Chunwang Li, Xiaojun Ma \\ College of Biochemical Engineering, Beijing Union University, Beijing, China \\ Email: ${ }^{\star}$ hce_137@163.com
}

How to cite this paper: Huang, C.-E., Li, C.W. and Ma, X.J. (2018) Active-DisturbanceRejection-Control for Temperature Control of the HVAC System. Intelligent Control and Automation, 9, 1-9.

https://doi.org/10.4236/ica.2018.91001

Received: January 6, 2018

Accepted: February 8, 2018

Published: February 11, 2018

Copyright $\odot 2018$ by authors and Scientific Research Publishing Inc. This work is licensed under the Creative Commons Attribution International License (CC BY 4.0).

http://creativecommons.org/licenses/by/4.0/

\section{(c) (i) Open Access}

\begin{abstract}
Heating, ventilation, and air conditioning (HVAC) system is significant to the energy efficiency in buildings. In this paper, temperature control of HVAC system is studied in winter operation season. The physical model of the zone, the fan, the heating coil and sensor are built. HVAC is a non-linear, strong disturbance and coupling system. Linear active-rejection-disturbance-control is an appreciate control algorithm which can adapt to less information, strong-disturbance influence, and has relative-fixed structure and simple tuning process of the controller parameters. Active-rejection-disturbance-control of the HVAC system is proposed. Simulation in Matlab/Simulink was done. Simulation results show that linear active-rejection-disturbance-control was prior to PID and integral-fuzzy controllers in rising time, overshoot and response time of step disturbance. The study can provide fundamental basis for the control of the air-condition system with strong-disturbance and high-precision needed.
\end{abstract}

\section{Keywords}

HVAC System, Linear Active-Rejection-Disturbance-Control, PID Control, Integral-Fuzzy Control, Temperature Control

\section{Introduction}

HVAC (heating, ventilation, and air conditioning, HVAC) is a typical complex system with non-linear, strong coupling and strong disturbance influence. The study on HVAC system is significant for the energy efficiency in buildings, and its control strategies are the major concern [1] [2]. Generally, PID control method is adapted in the temperature control of the zone in traditional HVAC system. The overshooting of the temperature often appears. When the special system has high requirement for the thermal and humidity of the zone, the over- 
shooting of the thermal and humidity cannot satisfy the high precision requirement, and the unnecessary energy consumption is produced. In order to solve the above problem, some researches on the control strategies of HVAC system are done, such as fuzzy control of a simple HVAC model [3] [4], tuning parameters of fuzzy control based on genetic algorithm in HVAC system [5]. Although the studies of HVAC system have obtained some good performances, there are some deficiencies.

Active-rejection-disturbance-control (ADRC) algorithm was proposed by Han Jingqing in 1998 [6]. Compared with traditional control approaches, ADRC shows good control performances, such as robustness [7], decoupling capability [8] [9], and so on. Some researches show that ADRC is suitable for the control of complex system with non-linear, strong coupling and disturbance rejection capabilities [10] [11] [12]. The main idea of ADRC approach is that the whole disturbances, including the internal and external, are actively estimated using an extended state observer (ESO) and compensated during each sampling period, and eliminated by controller.

Original ADRC consists of non-linear ESO and non-linear controller, and has strong robustness and disturbance rejection capabilities. However, the development of ADRC is limited by the complicated structure and difficult parameters tuning. In 2001, non-linear ADRC is simplified to linear active rejection disturbance control (LADRC) by Gao [13]. LADRC is simple, and the stability and disturbance rejection capabilities of ADRC are remained, and LADRC is applied widely. Some researches on ADRC of HVAC can be found. ADRC is applied in the temperature control of a zone in HVAC system [14] [15]. However, the structure of non-linear controller is complex and the tuning parameter is a problem.

In the paper, the physical model of HVAC system is built, including the zone, fan, heating coil, duct and sensor. LADRC with strong disturbance rejection capabilities, self-decoupling and simple structure is applied in temperature control of the HVAC system. The design of LADRC in the system is proposed. Simulation in Matlab/Simulink is done. Simulation results are compared with PID and Integral-Fuzzy control. Simulation results show that LADRC has priority to PID and integral-Fuzzy control in rising time, overshooting and rejecting the step disturbance. The study can provide fundamental basis for high-precision requirement, rejection strong disturbance and reduce energy consumption of HVAC system.

\section{HVAC Model}

In this paper, the temperature control of the HVAC system in winter operation season is chosen, when the disturbances of the system appear, in order to keep the temperature of the zone in $20^{\circ} \mathrm{C}$, actuator adjusts the water supply of internal coil of air handling unit. HVAC model is composed of zone, fan, heating coil and temperature sensor, the structural diagram is showed in Figure 1.

\subsection{Zone Model}

In this paper, a typical zone is chosen. Its volume is $36 \mathrm{~m}^{3}$. Two people with $150 \mathrm{~W}$ 


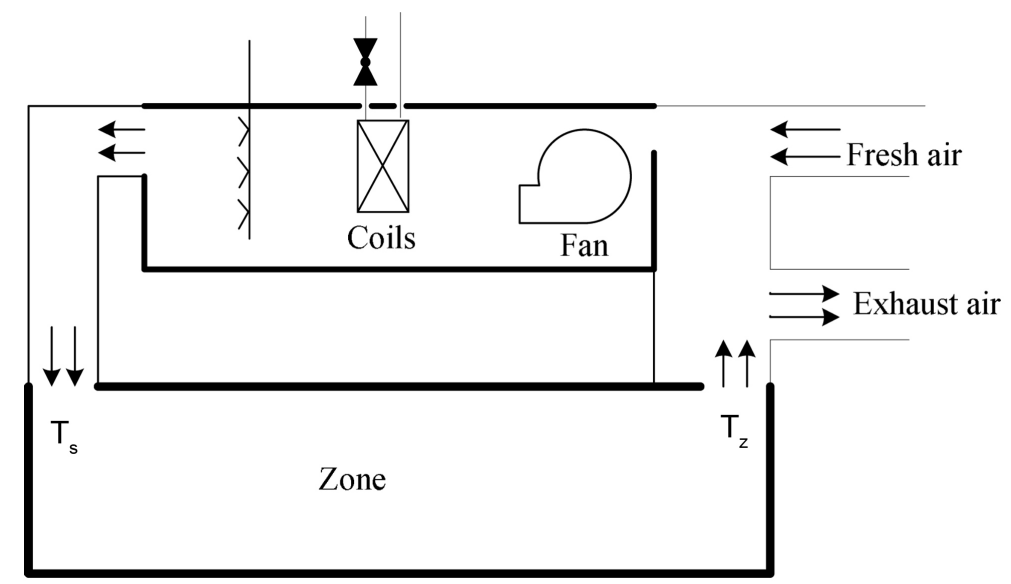

Figure 1. Structural diagram of the HVAC.

load and two lamps with load $500 \mathrm{~W}$ are considered. Based on energy and mass balance governing equations of the zone, the equation [5] can be obtained

$$
\rho_{a} C_{p a} V \frac{\mathrm{d} T_{z}}{\mathrm{~d} t}=m_{a} C_{p a}\left(T_{s}-T_{z}\right)+K F\left(T_{o}-T_{z}\right)+q(t)
$$

where its parameters is showed in Table 1.

The Laplace transform of the Equation (1) is:

$$
T_{z}(s)=G_{z}(s)\left[\lambda T(s)+\gamma T_{o}(s)+q(s)\right]
$$

where $G_{z}(s)=\frac{1}{\rho_{a} C_{p a} V s+m_{a} C_{p a}+K F}=\frac{1}{45.23 s+60.24}, \quad \lambda=m_{a} C_{p a}, \quad \gamma=K F$, the diagram of the zone is showed in Figure 2.

\subsection{Fan and Sensor Model [16]}

Heat transfer from the fan motor to air is considered, and causes air temperature to increase about $1^{\circ} \mathrm{C}-2^{\circ} \mathrm{C}$ normally. The transfer function of the fan is a first order function: $G_{F}(s)=\frac{1}{s+1}$. The sensor measure the actual temperature of the zone, and transfer to the controller for the control of the temperature, its transfer function is written as $G_{S}(s)=\frac{1}{s+1}$.

\subsection{Heating Coil Model [16]}

In this study, the winter operation season is chosen. Heating coil is water to air heat exchanger, which provides conditioned air for ventilation purposes in buildings. In order to build the simplified model of the heat coil, it has been assumed that the mass flow rate of the water inside the coil and the temperature of the air out from the coil are constants, the balance equation can be obtained:

$$
C_{a h} \frac{\mathrm{d} T_{c o}}{\mathrm{~d} t}=f_{s w} \rho_{w} C_{p w}\left(T_{w i}-T_{w o}\right)+(U A)_{a h}\left(T_{o}-T_{c o}\right)+f_{s a} \rho_{a} C_{p a}\left(T_{m}-T_{c o}\right)
$$

where the information of the parameters is described in Table 2. 
Table 1. Information of the parameters in Equation (1).

\begin{tabular}{cc}
\hline Parameters & Unit \\
\hline$\rho_{a}$ density of air & $\mathrm{kg} / \mathrm{m}^{3}$ \\
$C_{p a}$ specific heat of air & $\mathrm{kJ} /\left(\mathrm{kg} \cdot{ }^{\circ} \mathrm{C}\right)$ \\
$V$ volume of the zone & $\mathrm{m}^{3}$ \\
$T_{z}$ Temperature of the zone & ${ }^{\circ} \mathrm{C}$ \\
$m_{a}$ mass flow rate of the air stream & $\mathrm{kg} / \mathrm{s}$ \\
$T_{s}$ supply temperature & ${ }^{\circ} \mathrm{C}$ \\
$K$ heat transfer coefficient in the ambient & $\mathrm{W} /\left(\mathrm{m}^{2} \cdot{ }^{\circ} \mathrm{C}\right)$ \\
$F$ contact area of the wall and zone & $\mathrm{m}^{2}$ \\
$T_{o}$ temperature outside & ${ }^{\circ} \mathrm{C}$ \\
$q(t)$ heat gains from occupants, and light & $\mathrm{W}$ \\
\hline
\end{tabular}

Table 2. Information of the parameters in Equation (3).

\begin{tabular}{cc}
\hline Parameters & Unit \\
\hline$C_{a h}$ overall thermal capacitance of the air handling unit & $\mathrm{kJ} / \mathrm{C}$ \\
$T_{c o}$ temperature of the air out from the coil & ${ }^{\circ} \mathrm{C}$ \\
$f_{s W}$ water flow rate in coil & $\mathrm{m} / \mathrm{s} / \mathrm{m}^{3}$ \\
$\rho_{W}$ density of water & $\mathrm{kJ} /\left(\mathrm{kg} \cdot{ }^{\circ} \mathrm{C}\right)$ \\
$C_{p w}$ specific heat of water & ${ }^{\circ} \mathrm{C}$ \\
$T_{w i}$ supply water temperature & $\mathrm{kJ} /(\mathrm{s} \cdot \mathrm{C})$ \\
$(U A)_{a h}$ overall transmittance area factor of the air handling unit & $\mathrm{m} / \mathrm{s}$ \\
$f_{s a}$ volume flow rate of the supply air & ${ }^{\circ} \mathrm{C}$ \\
$T_{m}$ temperature in to the coil &
\end{tabular}

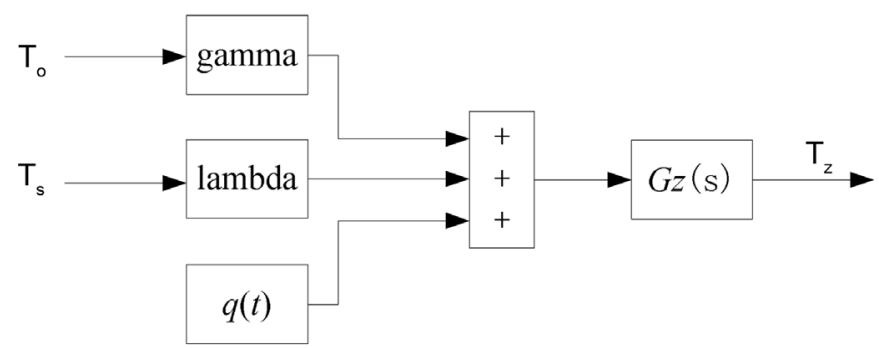

Figure 2. Diagram of the zone.

The Laplace transform of the Equation (3) is expressed by

$$
T_{c o}(s)=G_{A}(s)\left[\alpha T_{w i}(s)+(U A)_{a h} T_{o}(s)+\beta T_{m}(s)\right]
$$

where $G_{A}(s)=\frac{1}{C_{a h} s+\left[(U A)_{a h}+\beta\right]}=\frac{1}{4.5 s+0.28}$.

Similarly, the transfer function of the humidifier can be expressed by $G_{p}(s)=\frac{1}{0.63 s+0.21}$.

In this paper, the values of the parameters in the HVAC system are showed in 
Table 3.

\section{Temperature Control of the HVAC System}

\subsection{Active-Disturbance-Rejection-Control of the HVAC System}

In the temperature control of the zone, a first order ESO and second order controller of the LADRC are chosen, ESO is expressed by

$$
\left\{\begin{array}{l}
\dot{z}_{1}=z_{2}+\beta_{1}\left(-z_{1}+y\right)+b_{0} u \\
\dot{z}_{2}=\beta_{2}\left(-z_{1}+y\right)
\end{array}\right.
$$

where $u$ and $y$ are the input and output respectively, $\beta_{1}$ and $\beta_{2}$ are the gains of the observer, $z_{1}$ and $z_{2}$ are the estimators of the output $y$ and the whole disturbances, second order controller is expressed by

$$
\left\{\begin{array}{l}
u=\left(-z_{2}+u_{0}\right) / b_{0} \\
u_{0}=k_{p}\left(T_{r}-z_{1}\right)
\end{array}\right.
$$

The diagram of the LADRC is showed in Figure 3 and Figure 4.

\subsection{Integral-Fuzzy Control in the Temperature of HVAC System}

In practice, fuzzy control [17] is adopted in many process controls. The steady-state error of the output is a problem in traditional fuzzy controller. Hence, the error integral is added to the fuzzy controller in this study, the fuzzy controller is called integral-fuzzy controller.

Table 3. The parameter values in HVAC model.

\begin{tabular}{ccc}
\hline$C_{a h}=4.5 \mathrm{~kJ} / \mathrm{C}$ & $C_{p a}=1.005 \mathrm{~kJ} /\left(\mathrm{kg} \cdot{ }^{\circ} \mathrm{C}\right)$ & $F=30 \mathrm{~m}^{2}$ \\
$f_{s a}=0.192 \mathrm{~m}^{3} / \mathrm{s}$ & $C_{p w}=4.1868 \mathrm{~kJ} / \mathrm{kg} \cdot{ }^{\circ} \mathrm{C}$ & $\rho_{W}=988 \mathrm{~kg} / \mathrm{m}^{3}$ \\
$m_{a}=0.24 \mathrm{~kg} / \mathrm{s}$ & $K=2 \mathrm{~W} /\left(\mathrm{m}^{2} \cdot{ }^{\circ} \mathrm{C}\right)$ & $\rho_{a}=1.25 \mathrm{~kg} / \mathrm{m}^{3}$ \\
$V=36 \mathrm{~m}^{3}$ & $(U A)_{a h}=0.04 \mathrm{~kJ} /(\mathrm{s} \cdot \mathrm{C})$ & \\
\hline
\end{tabular}

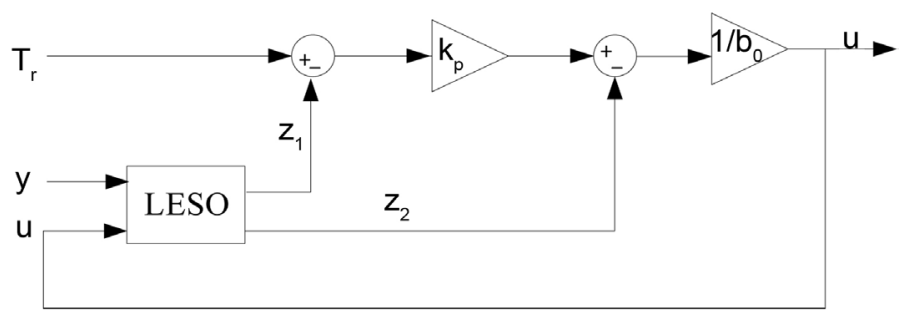

Figure 3. Diagram of LADRC.

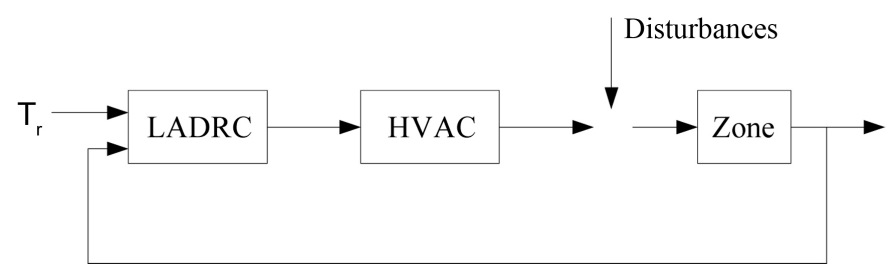

Figure 4. Structural diagram of LADRC for HVAC system. 
1) Design of the fuzzy controller

The inputs in the integral-fuzzy controller of the HVAC system are the error $e$ and its change-in-error $\mathrm{d} e / \mathrm{d} t$ of return air temperature $T_{z}$ and the set point of the temperature in the zone. The scale of the error $e \in[-2,2]\left({ }^{\circ} \mathrm{C}\right)$, the linguistic value of $e$ is expressed by \{neglarge, negsmall, zero, possmall, poslarge $=$ $\{\mathrm{NB}, \mathrm{NS}, \mathrm{ZE}, \mathrm{PS}, \mathrm{PB}\}$, membership function of the $e$ is triangle; the scale of $\mathrm{d} e / \mathrm{d} t \in[-0.5,0.5]$, the linguistic values of the $\mathrm{d} e / \mathrm{d} t$ is expressed by \{neglarge, negsmall, zero, possmall, poslarge $\}=\{\mathrm{NB}, \mathrm{NS}, \mathrm{ZE}, \mathrm{PS}, \mathrm{PB}\}$, membership function of the $\mathrm{d} e / \mathrm{d} t$ is triangle, the linguistic value of the output $u$ is the following \{close, minor-open, half-open, small-open, big-open $\}=\{\mathrm{CB}, \mathrm{CS}, \mathrm{M}, \mathrm{OS}, \mathrm{OB}\}$, membership function of the $u$ is trapezoid, the membership functions are drew in Table 4.

Rule base of the fuzzy controller is showed in Table 5.

Table 4. Membership functions of inputs and output for the fuzzy controller.

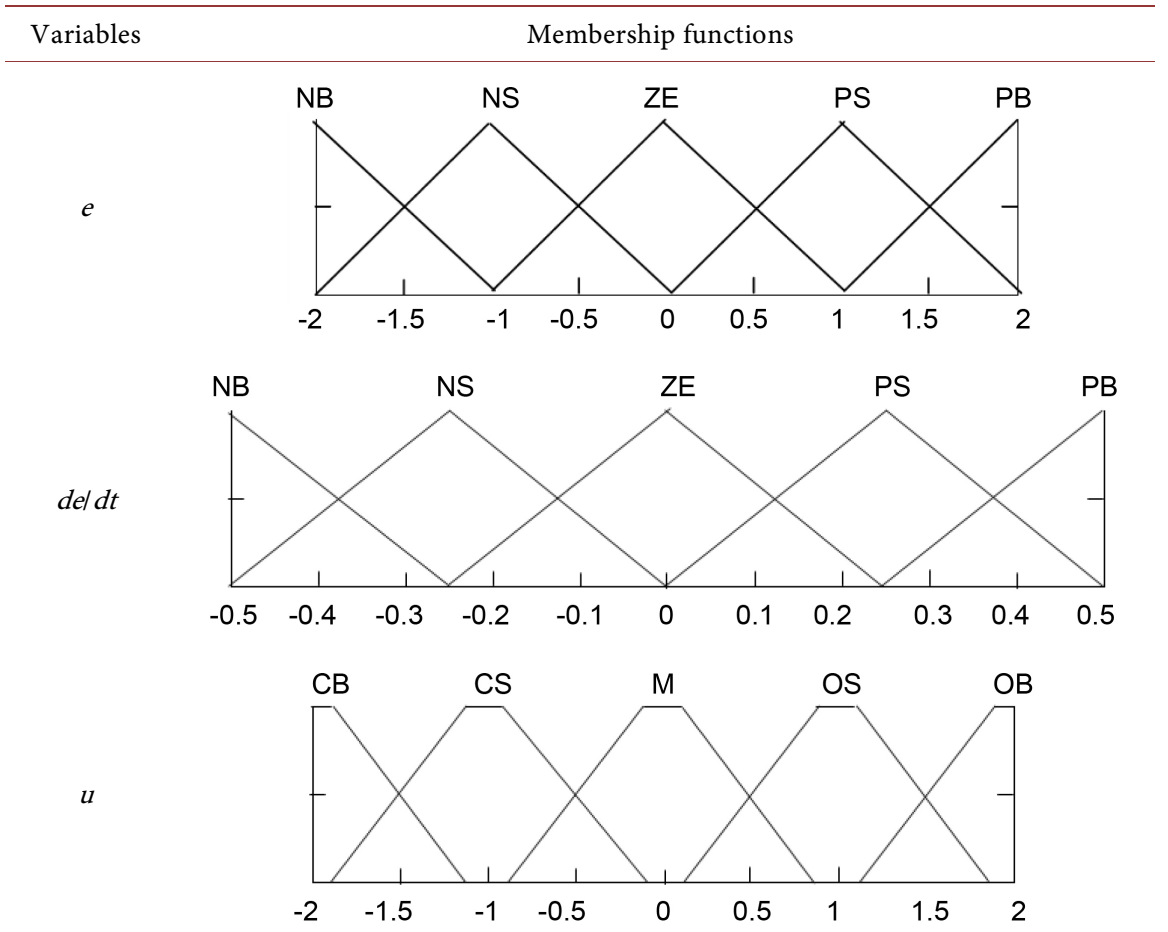

Table 5. Rule base of the fuzzy controller.

\begin{tabular}{ccccccc}
\hline & & & & $e$ & & \\
\cline { 3 - 7 } & & $N B$ & $N S$ & $Z E$ & $P S$ & $P B$ \\
\hline \multirow{3}{*}{$\mathrm{d} e / \mathrm{d} t$} & $N B$ & $O B$ & $O B$ & $O B$ & $O S$ & $C B$ \\
& $N S$ & $O B$ & $O S$ & $O S$ & $M$ & $C B$ \\
& $Z E$ & $O B$ & $O S$ & $M$ & $C S$ & $C B$ \\
& $P S$ & $O B$ & $M$ & $C S$ & $C S$ & $C B$ \\
& $P B$ & $O B$ & $C S$ & $C S$ & $C S$ & $C B$ \\
\hline
\end{tabular}




\section{2) Integral of the error}

In order to eliminate the steady-state error in the control of the HVAC system, the integral of the error is chosen as a part of the controller, the diagram of the integral-fuzzy controller is showed in Figure 5.

\subsection{Simulation of the HVAC System}

Supposed that the temperature outside is $0^{\circ} \mathrm{C}$, set point of the temperature of the zone is $20^{\circ} \mathrm{C}$, simulation modules are established in Matlab/Simulink environment, include the traditional PID controller, integral-fuzzy controller and LADRC. When the HVAC system approaches steady state, there are disturbances outside, such as open the door and windows, and so on. A step disturbance is added to the system in $\mathrm{t}=500 \mathrm{~s}$ in order to check the rejection disturbance capabilities. The tuning parameters of the controllers based on the experience is adapted, the values of the parameters is showed in Table 6.

Simulation result is showed in Figure 6, comparisons in overshot. Rising time and the rising time in step disturbance are showed in Table 7.

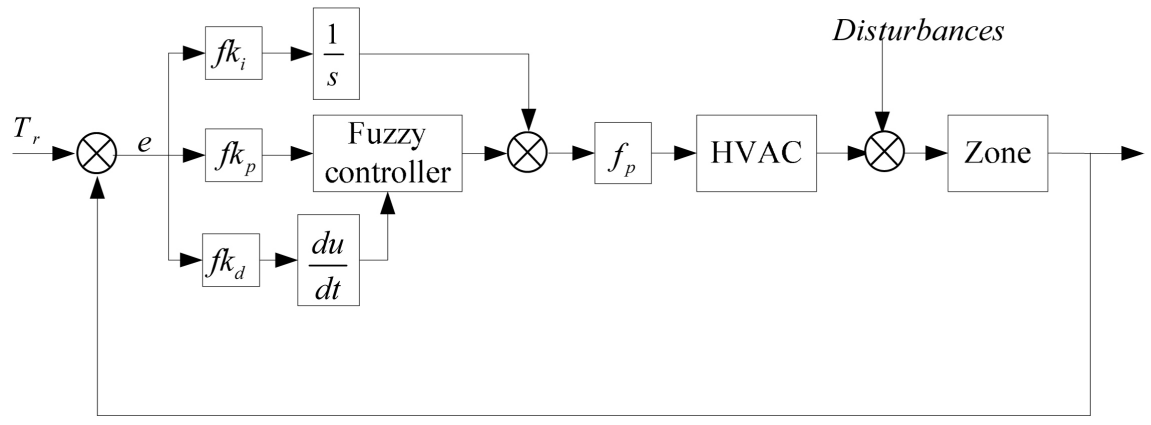

Figure 5. Diagram of the integral-fuzzy controller for HVAC system.

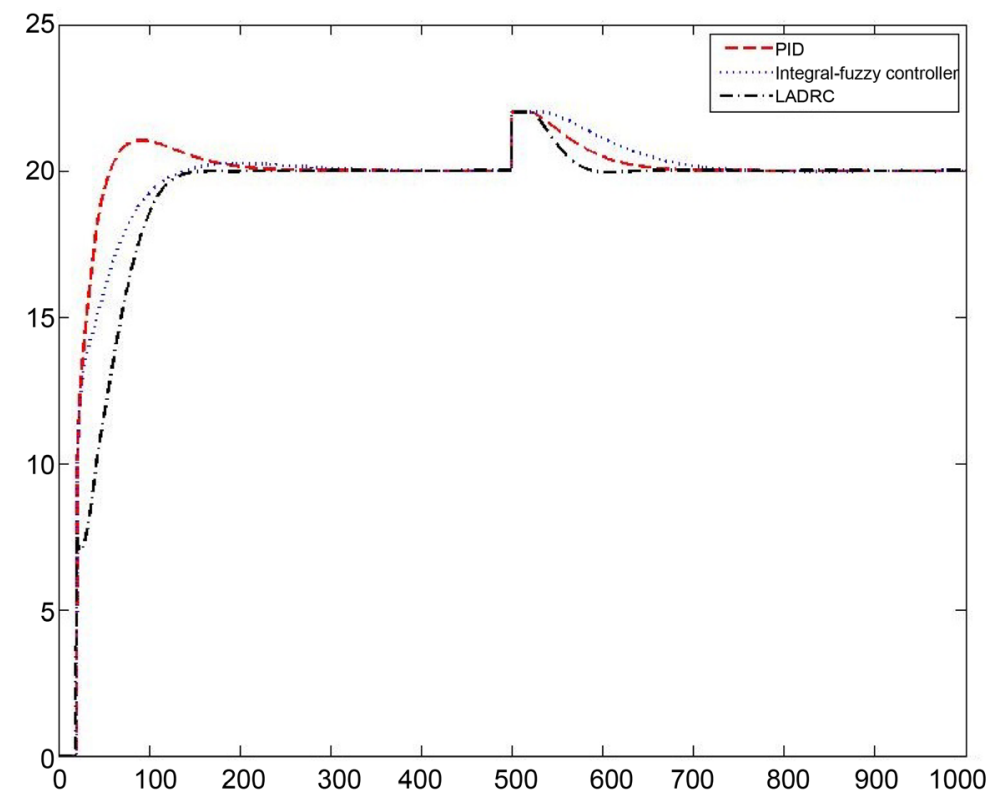

Figure 6. Simulation curves of HVAC system. 
Table 6. Parameters of the temperature controllers for the HVAC system.

\begin{tabular}{ccccc}
\hline Controller & \multicolumn{4}{c}{ Parameters } \\
\hline \multirow{2}{*}{ PID } & $k_{p}$ & $k_{i}$ & $k_{d}$ \\
& 2.3 & 0.15 & 6 & \\
LADRC & $b_{0}$ & $k_{p}$ & $\beta_{1}$ & $\beta_{2}$ \\
& 2.8 & 0.053 & 15 & 380 \\
Integral-Fuzzy controller & $f_{k p}$ & $f_{k d}$ & $f_{k i}$ & $f_{p}$ \\
& 2.20 & 0.70 & 0.20 & 0.5 \\
\hline
\end{tabular}

Table 7. Comparison belong three control methods of HVAC system.

\begin{tabular}{cccc}
\hline Controller & Rising time $(s)$ & Overshot $\left({ }^{\circ} \mathrm{C}\right)$ & $\begin{array}{c}\text { Rising time of the step } \\
\text { disturbance }(s)\end{array}$ \\
\hline PID & 240 & 1.04 & 180 \\
$\begin{array}{c}\text { Integral-Fuzzy } \\
\text { controller } \\
\text { LADRC }\end{array}$ & 340 & 0.27 & 235 \\
\hline
\end{tabular}

\section{Conclusion}

In the temperature control of the HVAC system, three approaches, including PID control, integral-fuzzy control and LADRC, are designed. Simulation results show that the LADRC obtains a good performance in the rising time and no overshooting; when the step disturbance is added to the system in $t=500 \mathrm{~s}$, the LADRC can quickly and smoothly reach the steady state in $80 \mathrm{~s}$ and shows good disturbance rejection capability. In the temperature control of the HVAC system, the LADRC represents in rising time, strong disturbance rejection and high precision. The study provides fundamental basis for the control of the HVAC system and energy conservation.

\section{References}

[1] Afram, A. and Janabi-Sharifi, F. (2014) Review of Modeling Methods for HVAC Systems. Applied Thermal Engineering, 67, 507-519. https://doi.org/10.1016/j.applthermaleng.2014.03.055

[2] Bai, X.L. and Yang, W.H. (2010) Evaluation Method and Application of Integrated Operation Energy Efficiency of Air-Conditioning System. Building Science, 26, 46-49. (In Chinese)

[3] Shen, G.M., Shu, G. and Wang, C.X. (2009) Simulation of Fuzzy Self-Tuning PID Control in AHU System. $A V \& C A, 39,138-140$. (In Chinese)

[4] Lin, X.Y., Shen, G.M. and Xie, J.L. (2007) Applications of Fuzzy Controller in Central Air-Conditioning Controlling System. Refrigeration and Air-Conditioning, 1, 47-50. (In Chinese)

[5] Rafael, A., et al. (2003) Fuzzy Control of HVAC Systems Optimized by Genetic Algorithms. Applied Intelligence, 18, 155-177. https://doi.org/10.1023/A:1021986309149

[6] Han, J.Q. (1998) Active-Disturbance-Rejection Controller and Its Applications. 
Control and Decision, 13, 19-23. (In Chinese)

[7] Gao, Z.Q. (2013) On the Foundation of Active Disturbance Rejection Control. Control Theory \& Applications, 30, 1499-1509. (In Chinese)

[8] Miklosovic, R. and Gao, Z. (2005) A Dynamic Decoupling Method for Controlling High Performance Turbo Fan Engine Shot. Process of the 16th IFAC World Congress, 38, 532-537.

[9] Zheng, Q., Chen, Z.Z. and Gao, Z.Q. (2009) A Practical Approach to Disturbance Decoupling Control. Control Engineering Practice, 17, 1016-1025. https://doi.org/10.1016/j.conengprac.2009.03.005

[10] Huang, C.-E, Li, D.H. and Xue, Y.L. (2013) Active Disturbance Rejection Control for the ALSTOM Gasifier Benchmark Problem. Control Engineering Practice, 21, 556-564. https://doi.org/10.1016/j.conengprac.2012.11.014

[11] Huang, Y. and Xue, W.C. (2011) Active-Disturbance-Rejection-Control: Methodology and Theoretical Analysis. Journal of System Science \& Mathematic Sciences, 31, 1111-1129. (In Chinese)

[12] Gao, Z. (2014) On the Centrality of Disturbance Rejection in Automatic Control. ISA Transactions, 53, 850-857. https://doi.org/10.1016/j.isatra.2013.09.012

[13] Gao, Z. (2003) Scaling and Bandwidth Parametrization Based Controller Tuning. Proceedings of the 2003 American Control Conference, Denver, CO, 4-6 June 2003, 4989-4996.

[14] Gu, K., Fu, D.X. and Wang, Y.G. (2014) Decoupling of the ADRC in Variable Air Volume Air Conditioning. Information Technology, 1, 24-27. (In Chinese)

[15] Shi, Y.C., Li, Z.J. and Lv, C. (2015) Temperature of Air Conditioning Spaces Based on Active Disturbance Rejection Control. Transactions of China Electrotechnical Society, 30, 439-444.

[16] Tashtoush, B., Molhim, M. and Al-Rousan, M. (2005) Dynamic Model of an HVAC System for Control Analysis. Energy, 30, 1729-1745.

https://doi.org/10.1016/j.energy.2004.10.004

[17] Zhu, J. (1995) The Theory and Applications of the Fuzzy Control. Mechanic Industry, Beijing. (In Chinese) 